2 Jessop J D, Currey H L F. Influence of gold salts on adjuvant arthritis in the rat. Ann Rheum Dis 1968; 27: 577-81.

3 Liyanage S P, Currey H L F. Failure of oral D-penicillamine to modify adjuvant arthritis or immune response in the rat. Ann Rheum Dis 1972; 31: 521 .

4 Jessop J D, Vernon-Roberts B, Harris J. Effects of gold salts and prednisolone on inflammatory cells. 1. Phagocytic activity of macrophages and polymorphs in inflammatory exudates studied by a 'skin-window' technique in rheumatoid and control patients. Ann Rheum Dis 1973; 32: 294-300.

\section{Rheumatoid arthritis and type 1 diabetes mellitus}

SIR, I read with interest the letter from Dr Rudge. ${ }^{1}$ We had reported a study ${ }^{2}$ in which we demonstrated an increased prevalence of type 1 diabetes and autoimmune thyroid disease in close relatives of patients with classical or definite rheumatoid arthritis. The rheumatoid patients demonstrated an increased prevalence of organ specific autoantibodies when compared to a control group with degenerative joint disease. We also included several pedigrees demonstrating the close relationship between rheumatoid arthritis and type 1 diabetes within some families. Dr Rudge's study was carried out at Nottingham along similar lines, but her study did not confirm our findings. It was mentioned by her that both the hospitals in which our study was carried out have an interest in the immunogenetics of these diseases and that this could attract the sort of cases we were interested in. In fact both rheumatology clinics service busy districts and there were very few referrals from outside our catchment areas. I suspect that this alone is not enough to explain the discrepancy.

Our original hypothesis was that the increased prevalence of type 1 diabetes in close relatives of rheumatoid patients could be predicted from the association both these diseases have with HLA DR4. We mentioned in the concluding paragraph of our paper that we would like to study HLA genotypes in families where one sibling had rheumatoid arthritis and another sibling had type 1 diabetes or other autoimmune endocrine disease. Since our paper was published we have studied some of the original families reported and others not included in the study; we have also studied some patients with coexistent type 1 diabetes and rheumatoid arthritis. Although this work is at a preliminary stage there is no clear association between these two diseases and HLA DR4 in the families and individual patients studied.

The pedigrees of families with coexistent rheumatoid arthritis and type 1 diabetes suggest a relationship between these two diseases, and we are confident that a mechanism for the common genetic susceptibility will be identified.

St Bartholomew's Hospital,

D. J. B. THOMAS

West Smithfield,

London EC1A 7BE

\section{References}

1 Rudge S. Rheumatoid arthritis and type 1 diabetes mellitus. Ann Rheum Dis 1983; 42: 603.
2 Thomas D J B, Young A, Gorsuch A N. Bottazzo G F, Cudworth A G. Evidence for an association between rheumatoid arthritis and autoimmune endocrine disease. Ann Rheum Dis 1983; 42: 297-300.

\section{Fatal bronchiolitis obliterans associated with chrysotherapy}

SIR, In the 'Discussion' section of their report of a case of fatal bronchiolitis obliterans (OB) associated with chrysotherapy Dr Holness and others ${ }^{1}$ state that a cystinuric patient given penicillamine succumbed to $O B$. The reference was to a letter of mine ${ }^{2}$ about penicillamine and $O B$. I had carried out a postal inquiry after deaths from $O B$ had been reported ${ }^{3}$ among patients with rheumatoid arthritis, some of whom had also been given penicillamine. In fact I failed to discover any further penicillamine-associated deaths from definite OB. One cystinuric patient had died from unspecified pulmonary disease which, in retrospect but without histological data, the reporting clinician thought might have been OB. I categorised this diagnosis as 'uncertain'. To the best of my knowledge this extremely doubtful case represents the only published reference to $O B$ as a complication of cystinuria or its treatment. Dr Holness, by omitting my qualifying comment that the diagnosis of $\mathrm{OB}$ in this instance was unlikely to have been correct quite unjustifiably made concrete what was insubstantial. The 'fact' that $\mathrm{OB}$ has been associated with penicillamine treatment of cystinuria may now (and probably will) seep further into the literature and become part of received opinion. The 'fact', Sir, is no fact, and I write in the faint hope that its transformation into undying myth may be aborted.

7 Astley Close, W. H. LYLE

Leamington Spa CV32 6PT

\section{References}

1 Holness L, Tenenbaum J, Cooter N B E, Grossman R F. Fatal bronchiolitis obliterans associated with chrysotherapy. Ann Rheum Dis 1983; 42: 593-6.

2 Lyle W H. D-penicillamine and fatal obliterative bronchiolitis. $\mathrm{Br}$ Med J 1977; i: 105

3 Geddes D M, Corrin B, Brewerton D A, Davies R J, TurnerWarwick M. Progressive airway obliteration in adults and its association with rheumatoid disease. $Q J$ Med 1977; 184: 427-44.

\section{Salicylate-NSAID interactions}

Sir, We were interested in the paper of Garrett and coworkers ${ }^{1}$ concerning interactions between salicylates and other NSAIDs using a rat model of inflammation. The authors found a lack of additive effect or antagonism between salicylates and most of the other NSAIDs tested, although they did not show whether this was likely to represent a pharmacokinetic or pharmacodynamic interaction.

In the previous study in patients with rheumatoid arthritis quoted by Garrettet al. there was no additive effect between 